\title{
Recurrent Chronic Myelomonocytic Leukemia
}

National Cancer Institute

\section{Source}

National Cancer Institute. Recurrent Chronic Myelomonocytic Leukemia. NCI Thesaurus.

Code C150048.

The reemergence of chronic myelomonocytic leukemia after a period of remission. 